\title{
All in the family
}

\author{
Bert Gordijn ${ }^{1} \cdot$ Henk ten Have ${ }^{2}$
}

Published online: 13 January 2020

(c) Springer Nature B.V. 2020

The Encyclopaedia Britannica defines the family as "a group of persons united by the ties of marriage, blood, or adoption, constituting a single household and interacting with each other in their respective social positions, usually those of spouses, parents, children, and siblings." (Encyclopaedia Britannica 2019). Historically, the family_as a social unithas undergone significant changes, for example as a result of technological innovations and associated societal transformations such as those during the Neolitic or the Industrial revolution. These changes to the social structure of the family have continued to occur in modern times as is evidenced by the rise of single-parent families, reconstituted families, same sex couples, cohabiting couples, and voluntary childless couples. Unsurprisingly, technological innovations and societal transformations have not only changed the social structure of the family. They have also altered its moral fabric and thus triggered new questions of family ethics. The first two papers in the issue at hand focus on two such questions. The first involves parental responsibilities, the second filial obligations.

\section{Parental responsibilities}

New reproductive technologies have changed reproduction-both when it comes to knowledge as well as in terms of control. Nowadays, prospective parents can access a lot more knowledge about what is going on at any given point in the reproductive process than has been possible at any earlier time in history. Pregnancies have become epistemically transparent. We can quite literally perceive the embryo in the womb, sequence its genome and observe its developing morphological characteristics. The amount of data and the quality of the information around reproductive trajectories,

\footnotetext{
Bert Gordijn

bert.gordijn@dcu.ie

Dublin City University, Dublin, Ireland

2 Duquesne University, Pittsburgh, USA
}

starting even before conception, has grown so much that it has triggered a discussion about the prospective parents' right not to know (cf. Sierawska 2015). Aspiring parents now have to decide to what extent the they wish to use available knowledge about certain aspects of their reproductive journey.

Together with improved knowledge, the possibilities to intervene in reproduction have developed immensely. Here also interventions are already possible before conception. Examples are contraceptive methods to prevent unintended pregnancies, and all kinds of assisted reproductive technologies such as cryopreservation of sperm and oocytes, artificial insemination, in-vitro fertilisation and surrogacy. In addition, there are lots of interventions-both before and during pregnancy - to lower the risks of neonatal and maternal mortality and morbidity (Lassi et al. 2014).

Increased knowledge and control mean enhanced parental responsibility. For example, it makes a difference when we know about certain negative effects of smoking during pregnancy in terms of sudden unexpected infant death cases (Anderson et al. 2019). The knowledge makes us more responsible, assuming we have some control over our smoking habit. Similarly, the availability of all kinds of prenatal and even preimplantation diagnostic interventions, enhances parental responsibility, presuming of course that parents know about these diagnostic possibilities.

Against this backdrop, Wallis (2020) asks whether it is ethical when parents select for deafness in their child. As you can read in the current issue, the author concludes that it may sometimes be ethical for parents to do just that (Wallis 2020). The point of this editorial, however, is that Wallis' question is rather new. It results from improved knowledge and enhanced parental control over the reproduction process, which occasion enhanced parental responsibilities and new ethical challenges. 


\section{Filial duties}

Traditionally there has been a certain symmetry in common sense morality around familial duties of care: we take it that parents ought to care for their children when they are young, whereas children are expected to take care of their parents when they are old and fragile. When there were hardly any specialised institutions, elderly care used to be organized by family members themselves within their own home. Nowadays however, filial care for parents is increasingly outsourced to professional organisations such as homecare networks, elderly care homes, and nursing homes.

This development has different causes. The average life span, for example, has grown dramatically (Max and OrtizOspina 2019). As a result, elderly now require longer lasting and more sophisticated care, which is often difficult to provide by non-professionals. In addition, family arrangements and logistics have changed, complicating homebased familial care for parents. The extended family of the past has been mostly replaced by smaller family structures. Paid workforce participation of women has remarkably expanded (Ortiz-Ospina and Tzvetkova 2017). Finally, it is not a given anymore that family members live nearby, because of increased mobility and globalisation. Hence, it is easy to see the advantages of outsourcing elderly care as it is less disruptive for the children's families, and the care is usually more professional and can be more beneficial for the parents.

As a consequence of the outsourcing of care though, a new ethical question has emerged. Supposing parents are cared for by professionals in a specialized institution, so there is no need any more for children to look after the parents for the purpose of providing care. Assuming further that dementia has caused parents not to be able to recognize their children anymore, are the children still obliged to visit their parents? If yes, what is the role of duties of sociability and those of expressing gratitude? In the second paper of this issue De Vries (2020) addresses these topical ethical questions - topical because many of us might have to ponder these questions in relation to our own parents, or we might ourselves end up in a residential care facility, unable to recognize our children.

\section{References}

Anderson, T.M., J.M.L. Ferres, S.Y. Ren, R.Y. Moon, R.D. Goldstein, J.M. Ramirez, and E.A. Mitchell. 2019. Maternal smoking before and during pregnancy and the risk of sudden unexpected infant death. Pediatrics 143 (4): e20183325. https://doi.org/10.1542/ peds.2018-3325.

Encyclopaedia Britannica, Family. Encyclopaedia Britannica. 2019. https://www.britannica.com/topic/family-kinship. Accessed 15 Dec 2019.

De Vries, B. 2020. 'I am your son, mother': severe dementia and duties to visit parents who can't recognise you. Medicine, Health Care and Philosophy. https://doi.org/10.1007/s11019-019-09931-5

Lassi, Z.S., T. Mansoor, R.A. Salam, J.K. Das, and Z.A. Bhutta. 2014. Essential pre-pregnancy and pregnancy interventions for improved maternal, newborn and child health. Reproductive Health 11 (1): S2.

Max, R., and Ortiz-Ospina, E. 2019. Life Expectancy. Our World in Data. https://ourworldindata.org/life-expectancy. Accessed 15 Dec 2019

Ortiz-Ospina, E., and Tzvetkova, S. 2017. Working Women: Key Facts and Trends in Female Labor Force Participation. Our World in Data. https://ourworldindata.org/female-labor-force-participationkey-facts. Accessed 15 Dec 2019.

Sierawska, A.K. 2015. Prenatal diagnosis: Do prospective parents have the right not to know? Medicine, Health Care and Philosophy 18 (2): 279-286.

Wallis, J.M. 2020. Is it ever morally permissible to select for deafness in one's child? Medicine, Health Care and Philosophy. https://doi. org/10.1007/s11019-019-09922-6.

Publisher's Note Springer Nature remains neutral with regard to jurisdictional claims in published maps and institutional affiliations. 